\title{
Salicylate-mediated suppression of jasmonate-responsive gene expression in Arabidopsis is targeted downstream of the jasmonate biosynthesis pathway
}

\author{
Antonio Leon-Reyes • Dieuwertje Van der Does • Elvira S. De Lange • \\ Carolin Delker - Claus Wasternack - Saskia C. M. Van Wees - Tita Ritsema • \\ Corné M. J. Pieterse
}

Received: 2 July 2010/Accepted: 17 August 2010/Published online: 14 September 2010

(C) The Author(s) 2010. This article is published with open access at Springerlink.com

\begin{abstract}
Jasmonates (JAs) and salicylic acid (SA) are plant hormones that play pivotal roles in the regulation of induced defenses against microbial pathogens and insect herbivores. Their signaling pathways cross-communicate providing the plant with a regulatory potential to finely tune its defense response to the attacker(s) encountered. In Arabidopsis thaliana, SA strongly antagonizes the jasmonic acid (JA) signaling pathway, resulting in the downregulation of a large set of JA-responsive genes, including the marker genes $P D F 1.2$ and $V S P 2$. Induction of JA-responsive marker gene expression by different JA derivatives was equally sensitive to SA-mediated suppression. Activation of genes encoding key enzymes in the JA biosynthesis pathway, such as $L O X 2, A O S, A O C 2$, and $O P R 3$ was also
\end{abstract}

A. Leon-Reyes - D. Van der Does - E. S. De Lange .

S. C. M. Van Wees · T. Ritsema · C. M. J. Pieterse ( $\square)$

Plant-Microbe Interactions, Department of Biology,

Faculty of Science, Utrecht University, P.O. Box 80056,

3508 TB Utrecht, The Netherlands

e-mail: C.M.J.Pieterse@uu.nl

A. Leon-Reyes

Universidad San Francisco de Quito (USFQ), Diego de Robles

y Vía Interoceánica (Cumbaya), P.O. Box 17-1200-841,

Quito, Ecuador

C. Delker · C. Wasternack

Leibniz Institute of Plant Biochemistry, 06120 Halle,

Weinberg 3, Germany

C. M. J. Pieterse

Centre for BioSystems Genomics, P.O. Box 98,

$6700 \mathrm{AB}$ Wageningen, The Netherlands

Present Address:

T. Ritsema

Amsterdam Molecular Therapeutics, Meibergdreef 61,

1100 DA Amsterdam, The Netherlands repressed by SA, suggesting that the JA biosynthesis pathway may be a target for SA-mediated antagonism. To test this, we made use of the mutant aos/dde2, which is completely blocked in its ability to produce JAs because of a mutation in the ALLENE OXIDE SYNTHASE gene. Mutant aos/dde2 plants did not express the JA-responsive marker genes PDF1.2 or VSP2 in response to infection with the necrotrophic fungus Alternaria brassicicola or the herbivorous insect Pieris rapae. Bypassing JA biosynthesis by exogenous application of methyl jasmonate (MeJA) rescued this JA-responsive phenotype in aos/dde2. Application of SA suppressed MeJA-induced PDF1.2 expression to the same level in the aos/dde2 mutant as in wild-type Col-0 plants, indicating that SA-mediated suppression of JAresponsive gene expression is targeted at a position downstream of the JA biosynthesis pathway.

Keywords Hormone crosstalk - Jasmonic acid · Plant defense $\cdot$ Salicylic acid

$\begin{array}{ll}\text { Abbreviations } \\ \text { AOS } & \text { Allene oxide synthase } \\ \text { JA } & \text { Jasmonic acid } \\ \text { JAs } & \text { Jasmonates } \\ \text { MeJA } & \text { Methyl jasmonate } \\ \text { SA } & \text { Salicylic acid }\end{array}$

\section{Introduction}

Plants are at constant risk of being attacked by a wide variety of insect herbivores and microbial pathogens. To defend themselves, plants possess a powerful innate 
immune system by which they recognize non-self molecules or signals from injured cells, and respond by activating an effective defense response (Jones and Dangl 2006; Howe and Jander 2008). The importance of the phytohormones salicylic acid (SA), jasmonic acid (JA), ethylene, and abscisic acid as primary signals in the regulation of the plant's immune response is well established (Pieterse et al. 2009; Verhage et al. 2010). Upon pathogen or insect attack, the quantity, composition, and timing of the phytohormonal blend produced by the plant depends greatly on the lifestyle and infection strategy of the invading attacker. This so-called 'signal signature' results in the activation of a specific set of defense-related genes that eventually determines the nature and effectiveness of the immune response that is triggered by the invader (De Vos et al. 2005). In recent years, molecular, genetic, and genomic tools have been used to uncover the complexity of the hormone-regulated induced defense signaling network. Besides balancing the relative abundance of different hormones, intensive interplay between hormone signaling pathways emerged as an important regulatory mechanism by which the plant is able to tailor its immune response to the type of invader encountered (Pieterse et al. 2009). Pathogens and insects, on the other hand, can manipulate the plant's defense signaling network for their own benefit by affecting phytohormone homeostasis to antagonize the host immune response (Pieterse and Dicke 2007; Walling 2008; Grant and Jones 2009)

JA, its structurally related metabolites, and the JA precursor 12-oxo-phytodienoic acid (OPDA) (here collectively called jasmonates, JAs) are lipid-derived compounds that upon pathogen or insect attack are rapidly synthesized via the oxylipin biosynthesis pathway (reviewed in Wasternack 2007; Gfeller et al. 2010). Mutants of Arabidopsis thaliana (Arabidopsis) defective in JA biosynthesis or signaling revealed important roles of JAs in defense against nectrotrophic pathogens and herbivorous insects (Browse 2009; Van der Ent et al. 2009b). ALLENE OXIDE SYNTHASE (AOS) emerged as a key enzyme in the JA biosynthesis pathway, since mutation of the single AOS gene in Arabidopsis leads to a complete elimination of JA production (Park et al. 2002; Von Malek et al. 2002). Upon synthesis, JA can be readily metabolized to the volatile methyl jasmonate (MeJA) through the activity of JA carboxyl methyltransferase (JMT) (Seo et al. 2001). In addition JA can be conjugated to amino acids such as isoleucine via the activity of the JA conjugate synthase JAR1 (Staswick and Tiryaki 2004), resulting in the biologically highly active form (+)-7-iso-jasmonoyl-L-isoleucine (JA-Ile) (Fonseca et al. 2009). The F-box protein COI1 (CORONATINE INSENSITIVE 1 ) is a key regulator of the JA signaling pathway (Chung et al. 2009).
It functions as a JA-Ile receptor in the E3 ubiquitin-ligase Skip-Cullin-F-box complex $\mathrm{SCF}^{\mathrm{COI1}}$ (Yan et al. 2009). Binding of JA-Ile to COI1 leads to degradation of JASMONATE ZIM-domain (JAZ) transcriptional repressor proteins via the proteasome (Chini et al. 2007; Thines et al. 2007). In resting cells, JAZ proteins act as transcriptional repressors of JA signaling by binding to positive transcriptional regulators, such as MYC2 (Chini et al. 2007). Hence, JAZ protein degradation results in de-repression of the JA signaling pathway and the activation of a large number of JA-responsive genes (Memelink 2009).

The JA-related transcriptome of Arabidopsis has been well studied. Strikingly, transcriptional changes in response to diverse JA-inducing biotic agents show limited overlap, suggesting that the context in which the JA signal is perceived is crucial in shaping the JA response (De Vos et al. 2005; Pozo et al. 2008; Pauwels et al. 2009). During plant interactions with pathogens and insects, the balance of different JA derivatives can rapidly change. Different JAs differentially activate JA responsive genes, which may fine-tune the JA response (Farmer et al. 2003; Gfeller et al. 2010). Moreover, JAs are often produced in combination with other hormones of which SA emerged as an important antagonist of the JA response (Koornneef and Pieterse 2008). Early studies in tomato revealed that SA and its acetylated form aspirin, are potent suppressors of the JA-dependent wound response (Doherty et al. 1988; Peña-Cortés et al. 1993). Also in Arabidopsis, SA was shown to suppress JA signaling, resulting in the downregulation of JA-responsive gene expression (Van Wees et al. 1999; Gupta et al. 2000; Spoel et al. 2003). In Arabidopsis, the JA-responsive marker genes PLANT DEFENSIN 1.2 (PDF1.2) and VEGETATIVE STORAGE PROTEIN 2 (VSP2) are highly sensitive to suppression by exogenous application of SA (Spoel et al. 2003; Koornneef et al. 2008; Leon-Reyes et al. 2009, 2010; Zander et al. 2009). This antagonism between SA and JA signaling was observed in a large number of Arabidopsis accessions collected from very different geographic origins (Koornneef et al. 2008), highlighting the potential significance of SA-JA crosstalk in nature. Indeed, trade-offs between SA-dependent resistance to biotrophic pathogens and JA-dependent defense against insect herbivory or infection by necrotrophic pathogens have been repeatedly reported (Bostock 2005; Verhage et al. 2010). In Arabidopsis, the SA pathway has been shown to inhibit JA-dependent resistance against the tissue-chewing herbivores Spodoptera exigua (beet armyworm) (Cipollini et al. 2004; Bodenhausen and Reymond 2007; Van Oosten et al. 2008), Spodoptera littoralis (Egyptian cotton worm) (Bruessow et al. 2010), and Trichoplusia ni (cabbage looper) (Cui et al. 2002), the cellcontent feeding insects Frankliniella occidentalis (Western flower thrips) (Leon-Reyes et al. 2009) and silverleaf 
whitefly (Bremia tabaci) (Zarate et al. 2007), and the necrotrophic fungus Alternaria brassicicola (Spoel et al. 2007; Leon-Reyes et al. 2009).

The antagonistic effect of SA on JA signaling in plants shows a remarkable resemblance to the effect of the antiinflammatory drug aspirin (acetyl-SA) on the formation of prostaglandins in animal cells. Prostaglandins are hormonal pain messengers that are structurally related to JAs and play a role in inflammation at sites of infection or tissue injury (Straus and Glass 2001). JAs and prostaglandins are both synthesized via the oxylipin biosynthesis pathway in which the enzymatic reactions leading to JA and prostaglandin formation are similar (Pan et al. 1998). In animal cells, aspirin antagonizes prostaglandin action by targeting enzyme activity and gene expression of CYCLOOXYGENASE (Straus and Glass 2001), the counterpart of AOS in plants. Although no inhibitory effect of SA on AOS enzyme activity has been observed in plants (Laudert and Weiler 1998), SA has been shown to suppress JA biosynthesis (Peña-Cortés et al. 1993; Spoel et al. 2003; Norton et al. 2007). Hence, antagonism of JA biosynthesis may be an important factor in the suppression of JA signaling by the SA pathway.

In Arabidopsis, induction of the JA response results in the activation of several JA biosynthesis genes, such as LOX2 (LIPOXYGENASE2), AOS, AOC2 (ALLENE OXIDE CYCLASE2), and OPR3 (12-OXO-PHYTODIENOATE REDUCTASE3) (Sasaki et al. 2001; Stenzel et al. 2003; Wasternack 2007). This indicates that JA biosynthesis is under the control of a positive feedback regulatory system, and that downregulation of JA biosynthesis gene expression by SA may be an important mechanism in SA-JA crosstalk. We reasoned that if the JA biosynthesis pathway is an important target of SA in the suppression of the JA signaling pathway, then Arabidopsis genotypes affected in JA biosynthesis should be significantly impaired in SA-mediated suppression of the JA response. In this study we tested this hypothesis and provided evidence that the antagonistic effect of SA on JA-dependent defense-related gene expression does not require downregulation of the JA biosynthesis pathway.

\section{Materials and methods}

Plant material

Seeds of $A$. thaliana genotypes were sown in quartz sand. Two-week-old seedlings were transferred to $60-\mathrm{mL}$ pots containing a sand/potting soil mixture that was autoclaved twice for $20 \mathrm{~min}$. Plants were cultivated in a growth chamber with an 8 -h day $\left(24^{\circ} \mathrm{C}\right)$ and 16 -h night $\left(20^{\circ} \mathrm{C}\right)$ cycle at $70 \%$ relative humidity for another 3 weeks. Plants were watered every other day and received half-strength Hoagland nutrient solution containing $10 \mathrm{mM}$ Sequestreen (Ciba-Geigy, Frankfurt, Germany) once a week. For all the experiments 5-week-old soil-grown plants were used. The following Arabidopsis genotypes were used: wild-type accessions Col-0, Col-5, and Ws-0 (Nottingham Arabidopsis Stock Centre, UK), mutants aos/dde2-2 [Col-0] (Von Malek et al. 2002), opr3 [Ws-0] (Stintzi and Browse 2000), aiml [Ws-0] (Richmond and Bleecker 1999), jarl-1 [Col0] (Staswick et al. 1992) and nprl-1 [Col-0] (Cao et al. 1994), AOC::RNAi lines 5 and 16 [Col-0] (Delker 2005), and the $L O X 2$ co-suppressed anti-sense transgenic line S-12 [Col-5] (Bell and Mullet 1993). The following T-DNA knockout lines [Col-0] were obtained from the SALK Institute Genomic Analysis Institute: SALK_140659 for opcl1 (At1g20510) (Koo et al. 2006) and At1g19640 Exotic line SM_3_35279 for jmt. Disruption of the JMT gene was checked by PCR using a specific primer for the insert (Spm32exotic FOR 5' - TAC GAA TAA GAG CGT CCA TTT TAG AGT GA $-3^{\prime}$ ) and a $J M T$-specific primer (JMT REV1 5'- TGT TTT TGG TAA TTT AAA CTA GTT TCT TG $\left.-3^{\prime}\right)$. Gene-specific primers for $J M T$ (JMT FOR2; 5'- GCA CCA ACT CCT AAG TGG CAA G -3'; JMT REV2; 5'-AAA GAA GCA AGG TAT GGC AGT AAA ACA TT- $3^{\prime}$ ) were used as controls for the endogenous gene. For seed production, sterility of the mutants aos/dde2 and opr3 was restored by exogenous application of MeJA to the flowers as described (Stintzi and Browse 2000; Park et al. 2002; Von Malek et al. 2002).

Pathogen and insect assays

Alternaria brassicicola strain MUCL 20297 was grown on potato dextrose agar (PDA; Difco Laboratories, Detroit, MI, USA) plates for 2 weeks at $22^{\circ} \mathrm{C}$ and conidia were subsequently collected as described (Broekaert et al. 1990). Plants were inoculated when 5 weeks old by applying $5 \mu \mathrm{L}$ droplets of half-strength potato dextrose broth containing $5 \times 10^{5}$ spores per $\mathrm{mL}$, as described previously (Van der Ent et al. 2008). After inoculation, plants were kept at $100 \%$ relative humidity for optimal infection. Hyaloperonospora arabidopsidis strain WACO9 was cultivated and used for plant inoculations as described (Van der Ent et al. 2009a). In the multi-attacker experiment, $H$. arabidopsidis was inoculated $72 \mathrm{~h}$ prior to Alternaria brassicicola. Pieris rapae were reared as described previously (De Vos et al. 2005) and transferred to 5-week-old plants. Infestation was carried out by transferring five first-instar larvae of $P$. rapae to each plant using a fine paintbrush. 


\section{Chemical treatments}

Plants were treated with SA (Mallinckrodt Baker, Deventer, The Netherlands) and/or MeJA (Duchefa Biochemie BV, Haarlem, The Netherlands) by dipping the leaves into a solution of $0.015 \%$ (v/v) Silwet L77 (Van Meeuwen Chemicals BV, Weesp, The Netherlands) containing $0.1 \mathrm{mM} \mathrm{MeJA}$, $1 \mathrm{mM}$ SA or a combination of both chemicals as described previously (Spoel et al. 2003; Leon-Reyes et al. 2009). Control treatments were dipped into a solution containing $0.015 \%$ (v/v) Silwet L77. MeJA was added to the solutions from a 1,000 -fold concentrated stock in $96 \%$ ethanol. To the solutions without MeJA, a similar volume of $96 \%$ ethanol was added. Treatments with $0.1 \mathrm{mM}$ linolenic acid (LA) (Sigma-Aldrich, St. Louis, USA), OPDA, JA, and JA-Ile were performed as described for MeJA. The compounds were synthesized as described (Miersch et al. 2008; Fonseca et al. 2009).

RNA extraction and Northern-blot analysis

For RNA extraction, at least five plants per treatment were harvested at the time points indicated. RNA isolation and Northern-blot analysis were performed, as described previously (Van Wees et al. 1999). Northern blots were hybridized with gene-specific probes for PR-1 (At2g14610), PDF1.2 (At5g44420), VSP2 (At5g24770), LOX2 (At3g45140), and $18 S$ rRNA as described (Van Wees et al. 1999; Pozo et al. 2008). Probes for the genes AOS (At5g42650), OPR3 (At2g06050), and AOC2 (At3g25770) were made by PCR amplification on cDNA that was synthesized from mRNA which was isolated from MeJA-treated Arabidopsis plants. Primers used for the amplification of gene-specific probes were: $A O S$-FOR $5^{\prime}$-CCC TTT TCC GAT TTC TCT CC-3' and $A O S$-REV 5'-ACG GTA GCC TCC GGT TAG TT-3', $O P R 3$-FOR $5^{\prime}$-AAA ACA GGT GGC GAG TTT TG- $3^{\prime}$ and OPR3-REV 5'-GCC TTC CAG ACT CTG TTT GC-3', $A O C 2$-FOR $5^{\prime}$-GCC AAG AAG AAC CTC ACT GC- $3^{\prime}$ and AOC2-REV 5'-GGC ACC TTC AAA GAT TCC AG-3'. To check for equal loading, blots were stripped and hybridized with a probe for $18 S$ ribosomal RNA. After hybridization with $\alpha-{ }^{32} \mathrm{P}-\mathrm{dCTP}$-labeled probes, blots were exposed for autoradiography. Signal intensities of probes were quantified using a BioRad Molecular Imager FX with Quantity One software (BioRad, Veenendaal, The Netherlands). All gene expression analyses were repeated with similar results.

\section{Results}

SA-mediated suppression of JA biosynthesis genes

In Arabidopsis, pharmacological experiments revealed that SA can antagonize the expression of JA-responsive genes, such as the marker gene PDF1.2 (Spoel et al. 2003). Figure 1a shows that, while the expression of the SAresponsive marker gene PR-1 (PATHOGENESIS RELA$T E D-1)$ is upregulated, MeJA-induced expression of $P D F 1.2$ is strongly suppressed within $3 \mathrm{~h}$ after application of SA. Also when PDF1.2 transcription was activated by the JA precursor LA, or the JAs OPDA, JA, or JA-Ile, the expression level of PDF1.2 was strongly antagonized by SA (Fig. 1c). Moreover, during simultaneous interaction with the SA-inducing biotrophic downy mildew pathogen $H$. arabidopsidis and the JA-inducing necrotrophic fungus Alternaria brassicicola, JA-responsive PDF1.2 transcription was suppressed, while SA-responsive $P R-1$ expression was unaffected (Fig. 1b). These results confirm the notion that biological or chemical activation JA-responsive gene expression in Arabidopsis is antagonized by the SA pathway.

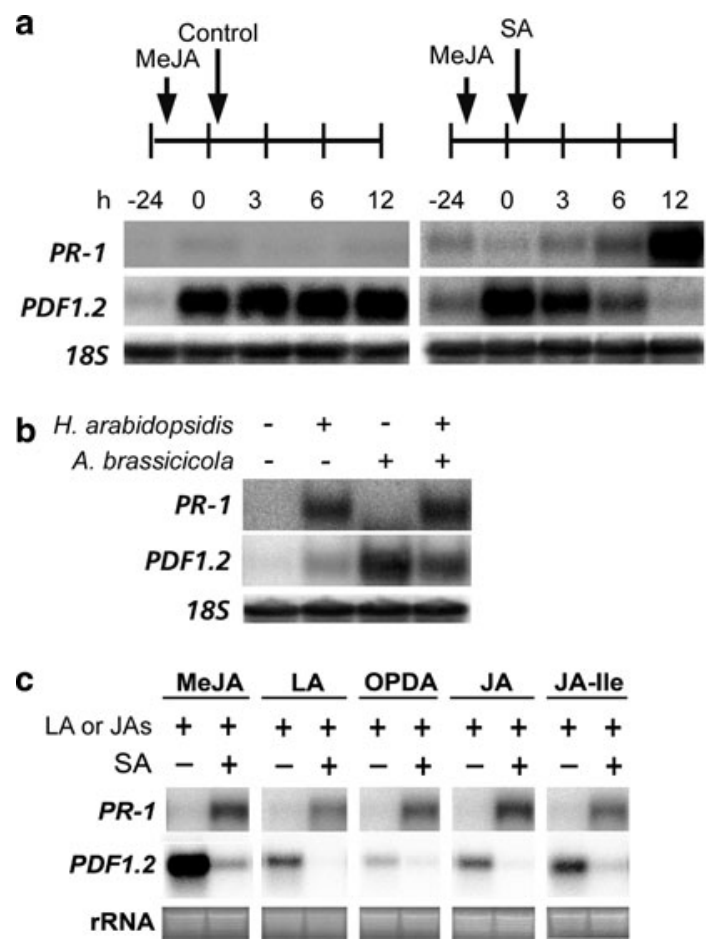

Fig. 1 SA-mediated suppression of the JA-responsive marker gene PDF1.2 in Arabidopsis. a Northern-blot analysis of transcript levels of the SA-responsive $P R-1$ gene and the JA-responsive $P D F 1.2$ gene in 5-week-old Arabidopsis Col-0 plants that were treated with $0.1 \mathrm{mM}$ MeJA and $24 \mathrm{~h}$ later with either water (control) or $1 \mathrm{mM} \mathrm{SA}$. Leaves were harvested at the indicated time points. b $P R-1$ and $P D F 1.2$ transcript levels in 5-week-old Arabidopsis plants that were first inoculated with the SA-inducing biotroph $H$. arabidopsidis and $72 \mathrm{~h}$ later with the JA-inducing necrotroph Alternaria brassicicola. Leaves were harvested $24 \mathrm{~h}$ after Alternaria brassicicola inoculation. c $P R-1$ and $P D F 1.2$ transcript levels in 5-week-old Arabidopsis plants $24 \mathrm{~h}$ after treatment with $0.1 \mathrm{mM}$ of MeJA, LA, OPDA, JA or JA-Ile, and either water or $1 \mathrm{mM}$ SA. Equal loading of RNA samples was checked using a probe for $18 \mathrm{~S}$ rRNA or by ethidium bromide staining of the RNA gel 

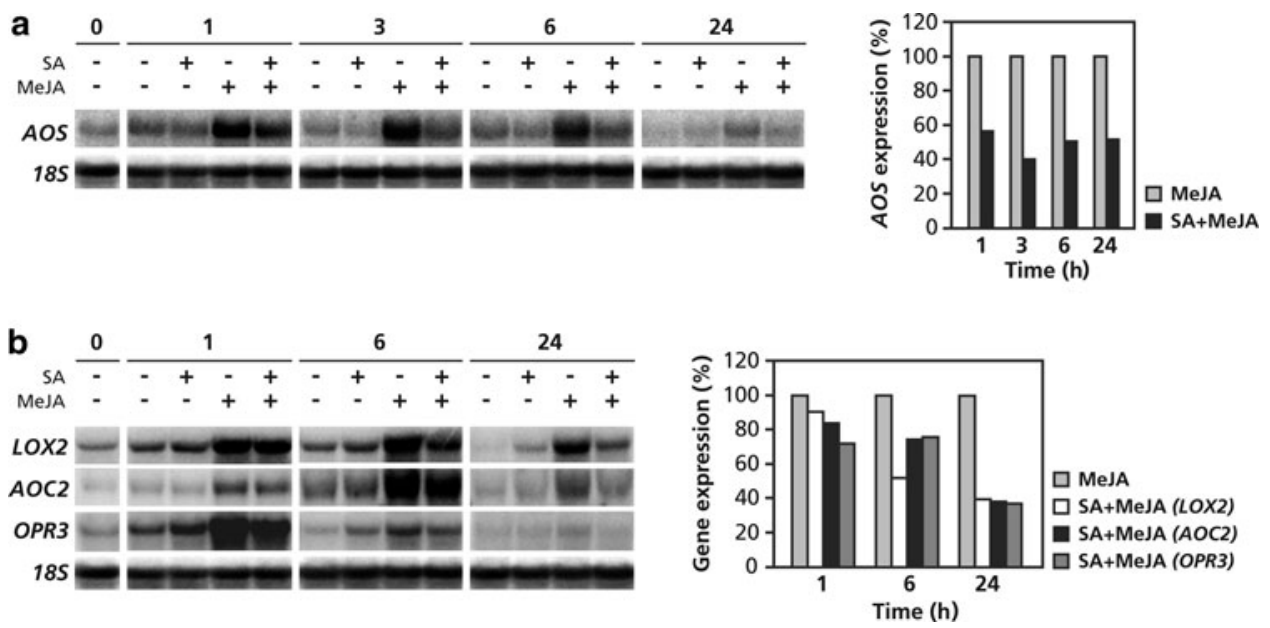

Fig. 2 SA-mediated suppression of the JA biosynthesis genes AOS, $L O X 2, A O C 2$, and $O P R 3$. Northern-blot analysis of transcript levels of the JA biosynthesis genes AOS (a) and LOX2, AOC2, and OPR3 (b) in 5-week-old Arabidopsis Col-0 plants that were treated at time point $0 \mathrm{~h}$ with $1 \mathrm{mM} \mathrm{SA}, 0.1 \mathrm{mM}$ MeJA, or with a combination of both chemicals. Leaves were harvested at the indicated time points. Equal loading of RNA samples was checked using a probe for $18 \mathrm{~S}$

To investigate whether JA-responsive expression of the JA biosynthesis genes $A O S, L O X 2, A O C 2$, and $O P R 3$ can be antagonized by SA, 5-week-old wild-type Col-0 plants were treated with MeJA, SA or with a combination of both chemicals. Figure 2a shows that SA suppressed the MeJAinduced expression level of $A O S$ as early as $1 \mathrm{~h}$ after treatment. Also at later time points $A O S$ gene expression remained suppressed in the combination treatment. For better visualization of the suppressive effect of SA on MeJA-induced AOS expression we quantified the signal intensities of the Northern blot depicted in Fig. 2a using a Phosphor imager (Fig. 2a, right panel). At all time points tested, AOS transcript levels in SA + MeJA-treated plants were $40-50 \%$ of that in the MeJA-treated plants. Figure $2 \mathrm{~b}$ shows that MeJA-induced expression of $L O X 2, A O C 2$, and $O P R 3$ was also sensitive to suppression by SA. At 1 and $6 \mathrm{~h}$ after MeJA treatment, the level of suppression by SA was not as pronounced as for $A O S$, but at $24 \mathrm{~h}$ after induction the level of suppression was comparable to that observed for $A O S$. From these results we conclude that the JA biosynthesis genes $A O S, L O X 2, A O C 2$, and $O P R 3$ are sensitive to suppression by SA.

\section{PDF1.2 gene expression in JA biosynthesis mutants}

We reasoned that if the antagonistic effect of SA on JA signaling can be explained by the suppressive effect of SA on the JA biosynthesis pathway, then Arabidopsis genotypes affected in JA production would be impaired in crosstalk between SA and JA signaling. To investigate this, we needed a JA biosynthesis mutant that was fully blocked
rRNA. Signal intensities of the Northern blots in the left panels were quantified using a Phosphor imager (right panels). Transcript levels in the single MeJA treatments were set to $100 \%$. Please note that the quantitative data displayed in the right panels are quantifications of the corresponding signal intensities in the left panels and thus do not contain error bars. The Northern-blot analyses have been repeated with similar results

in JA-resonsive gene expression upon endogenous stimulation of the JA pathway, but displayed wild-type levels of expression upon exogenous application of MeJA. To this end, we first screened previously characterized Arabidopsis mutants and transgenic lines that are impaired in different steps of the JA biosynthesis pathway for their ability to activate PDF1.2 upon MeJA treatment or inoculation with the necrotrophic fungus Alternaria brassicicola. Arabidopsis lines S-12, aos/dde2, AOC::RNAi lines 5 and 16, opr3, aiml, opcl1, jmt, and jarl, which are affected at different steps in the JA biosynthesis pathway (Fig. 3a), showed wild-type levels of PDF1.2 expression upon exogenous application of MeJA (Fig. 3b). Because MeJA treatment bypasses the JA biosynthesis pathway, these results confirm that downstream of JA biosynthesis the JA signaling pathway is fully functional in these genotypes.

Previously, we demonstrated that Alternaria brassicicola induces high levels of JA in Arabidopsis (De Vos et al. 2005). Upon inoculation with Alternaria brassicicola, PDF 1.2 transcripts were readily detectable in wild-type Col-0, Col-5, and Ws-0 plants (Fig. 3b). Although to a lesser extent, the majority of the genotypes affected in JA biosynthesis also activated PDF1.2 upon inoculation with Alternaria brassicicola, indicating that they are either leaky, or still able to produce biologically active oxylipins. In the case of the two AOC::RNAi lines we detected still about 20\% JA and OPDA compared to the wild type following wounding of leaves (data not shown). Similarly, JA-responsive gene expression in mutant aiml may reflect the residual oxylipin formation as detected upon wounding (Delker et al. 2007). The AOS mutant aos/dde2 was the 
Fig. 3 Characterization of JAresponsive $P D F 1.2$ and $V S P 2$ expression in JA biosynthesis mutants. a JA biosynthesis pathway and corresponding Arabidopsis genotypes that are affected in JA biosynthesis. b-d Northern-blot analysis of PDF 1.2 or VSP2 transcript levels in 5-week-old Arabidopsis plants that were treated with $0.1 \mathrm{mM} \mathrm{MeJA}$, inoculated with the necrotrophic fungus Alternaria brassicicola, or infested with the insect herbivore $P$. rapae. Genotypes in the Ws-0 background (opr3, aim1); genotypes in the Col-0 background (aos/dde2,

AOC::RNAi lines 5 and 16, opcl1, jmt, and jarl); genotype in Col-5 background (S-12). Leaf tissue was harvested $24 \mathrm{~h}$ after treatment with MeJA, inoculation with Alternaria brassicicola, or infestation with $P$. rapae. Equal loading of RNA samples was checked using a probe for $18 S$ rRNA (data in b only given for Col-0, but were similar for all other genotypes). Northern-blot analyses have been repeated with similar results

\section{a}
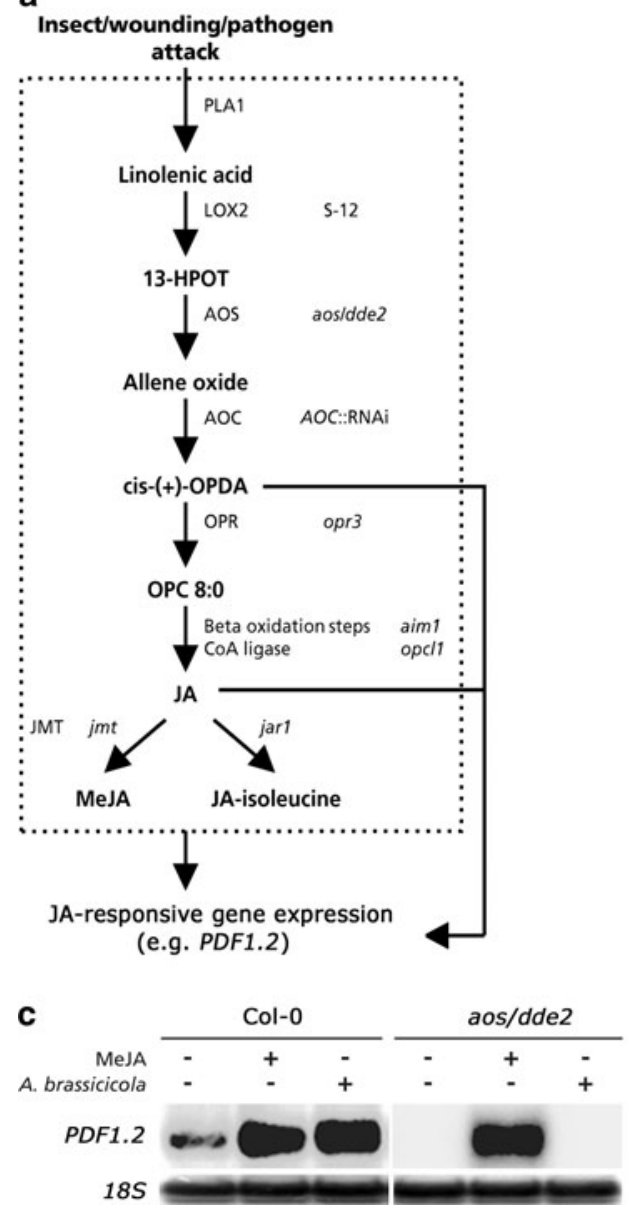

b
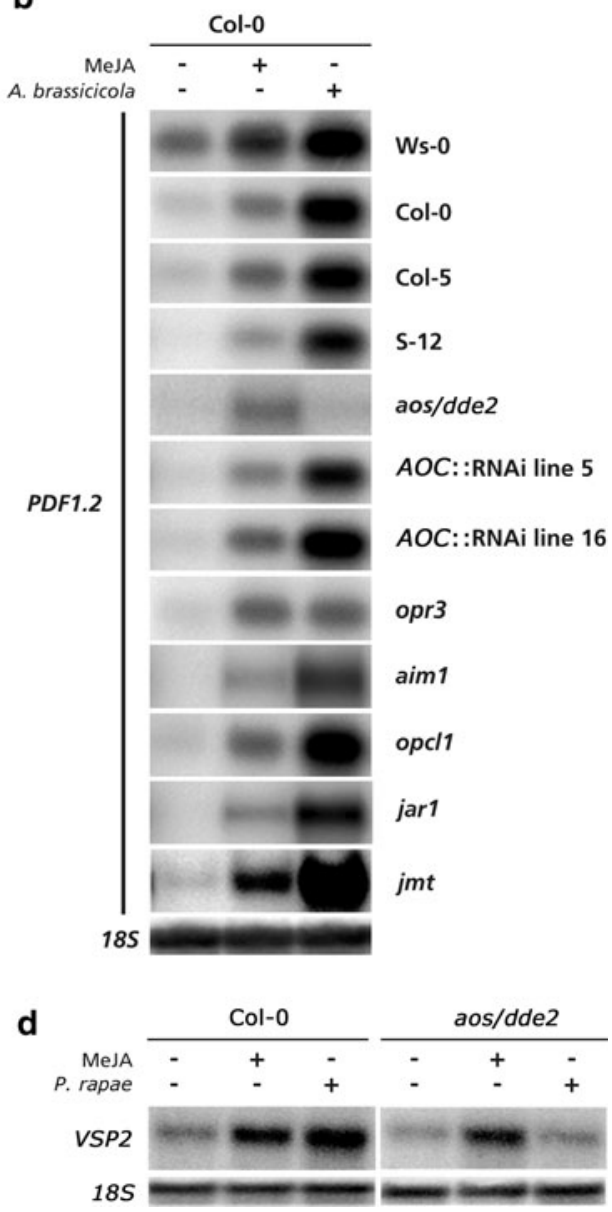

only genotype that was fully blocked in its capacity to express PDF1.2 upon pathogen infection. At the same time, it showed normal levels of PDF1.2 expression after MeJA treatment (Fig. 3b). In a control experiment, the inability of $a o s / d d e 2$ to activate PDF1.2 upon inoculation with Alternaria brassicicola was confirmed (Fig. 3c). Also the induction of the JA-responsive marker gene VSP2 upon feeding by larvae of the insect herbivore $P$. rapae (small cabbage white) was blocked in this mutant (Fig. 3d). Hence, mutant aos/dde2 was used to assess whether the antagonistic effect of SA on JA signaling is affected in plants that are unable to produce JAs.

SA antagonizes JA signaling downstream of the JA biosynthesis pathway

To investigate whether down-regulation of the JA biosynthesis pathway is a central target of SA in the suppression of JA signaling, we tested the ability of aos/dde 2 to display SA-JA crosstalk. Figure 4a shows that exogenous application of MeJA or SA to wild-type Col-0 and mutant aos/ dde2 plants induced similar levels of PDF1.2 and PR-1 transcription, respectively. When applied in combination with MeJA, SA strongly suppressed the expression of PDF1.2 in both Col-0 and aos/dde2. Hence, SA-mediated suppression of MeJA-induced PDF1.2 expression is fully functional in the JA biosynthesis mutant aos/dde2. Moreover, SA was also able to suppress MeJA-induced PDF1.2 transcription in the Arabidopsis genotypes S-12, $A O C:$ RNAi lines 5 and 16, opr3, aim1, opcl1, jmt and jarl, in most cases to similar levels as in their respective wild-types (Fig. 4b). In the negative control mutant nprl, which is blocked in SA-mediated suppression of JAresponsive gene expression, $P D F 1.2$ was not suppressed by SA, confirming previous findings (Spoel et al. 2003; LeonReyes et al. 2009). Collectively, these results indicate that SA antagonizes JA signaling via a target downstream of the JA biosynthesis pathway.

Although the combination treatment of SA and MeJA consistently led to suppression of MeJA-induced PDF1.2 expression and generally did not affect the level of $P R-1$ expression, occasionally a synergistic effect on SA-induced $P R-1$ expression was observed. For instance, the combination treatment displayed in Fig. $4 \mathrm{~b}$ shows an enhanced level of $P R-1$ mRNA accumulation in the genotypes S-12, $A O C$ RNAi line 16, and aiml when compared to the 

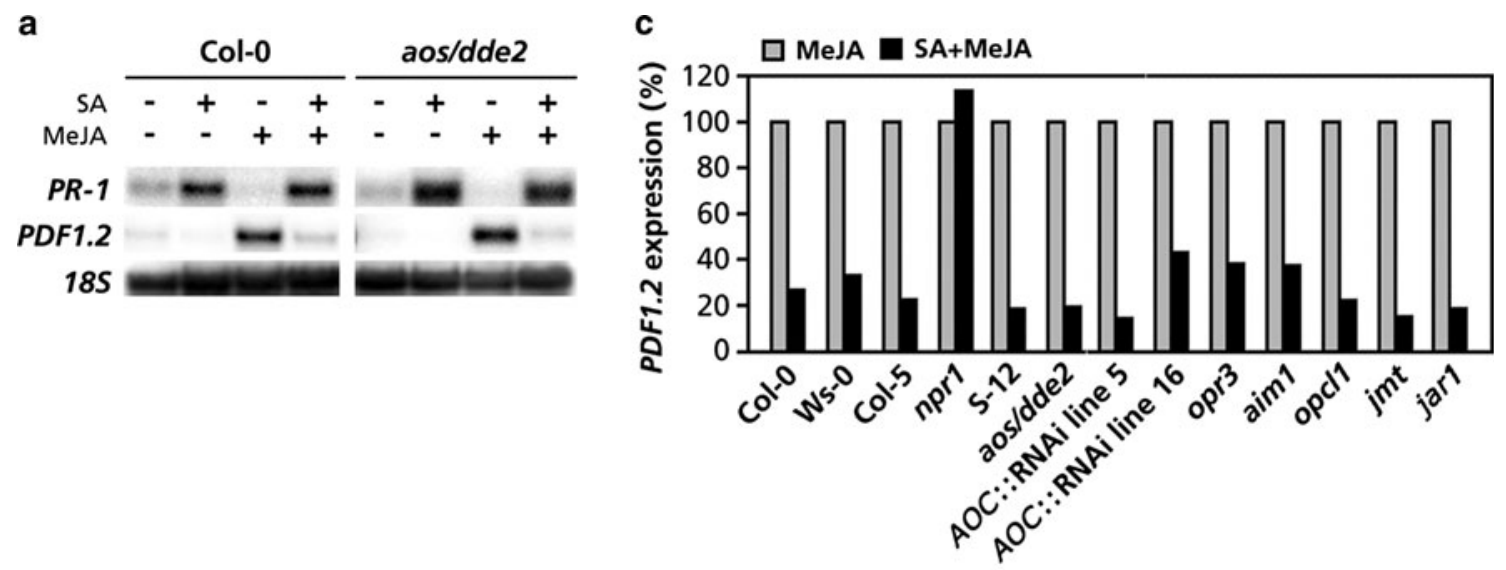

b
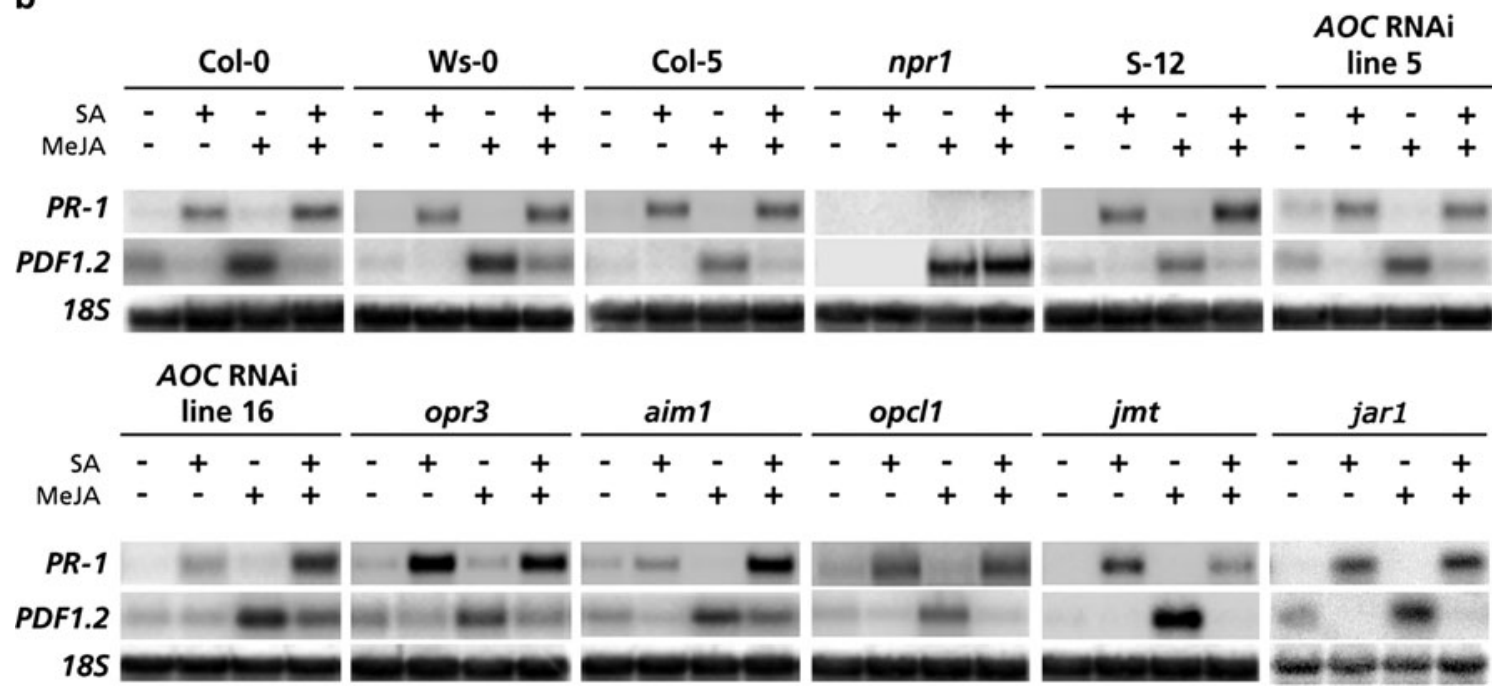

Fig. 4 Antagonistic effect of SA on $P D F 1.2$ expression in JA biosynthesis mutants. a, b Northern-blot analysis of $P R-1$ and $P D F 1.2$ transcript levels in 5-week-old Arabidopsis plants that were treated with $1 \mathrm{mM} \mathrm{SA}, 0.1 \mathrm{mM}$ MeJA, or a combination of both chemicals. For details on the JA biosynthesis mutants used, see legend to Fig. 3. Mutant $n p r l$ was used as a negative control for SA-JA cross-talk. Leaf tissue was harvested $24 \mathrm{~h}$ after treatment for RNA analysis.

respective single SA treatment. Because these genotypes show an altered oxylipin signature, it is tempting to speculate that this is caused by the hormonal context in which the SA response is triggered. This is in line with previous observations by Mur et al. (2006) who demonstrated that JA can synergistically enhance SA-induced $P R-1$ gene expression, depending on the respective concentrations of the hormones.

\section{Discussion}

Plant immunity is regulated by a complex network of crosscommunicating signaling pathways. The plant hormones SA and JA play crucial roles in controlling plant defenses that are triggered after pathogen or insect attack. The SA and JA
Equal loading of RNA samples was checked using a probe for $18 \mathrm{~S}$ rRNA. c Quantification of the signal intensities of the Northern blots in $\mathbf{a}$ and $\mathbf{b}$ using a Phosphor imager. PDF1.2 transcript levels in the single MeJA treatments were set to $100 \%$. Please note that the quantitative data displayed in $\mathbf{c}$ are quantifications of the corresponding signal intensities in $\mathbf{a}$ and $\mathbf{b}$ and thus do not contain error bars. The Northern-blot analyses have been repeated with similar results

signaling pathways are often mutually antagonistic, but the outcome of the signal interaction greatly depends on the context in which they are activated (Pieterse et al. 2009). Early studies in tomato demonstrated that exogenous application of SA suppresses the expression of JA biosynthesis genes, suggesting that SA may target the JA biosynthesis pathway to suppress downstream JA signaling (Peña-Cortés et al. 1993). Previously, Spoel et al. (2003) demonstrated that SA-nonaccumulating Arabidopsis NahG plants produced significantly more JA in response to infection by the SA- and JA-inducing pathogen Pseudomonas syringae pv. tomato DC3000, suggesting that in wild-type Arabidopsis plants SA exerts a suppressive effect on the JA biosynthesis pathway. However, in a study on the interaction between Arabidopsis and the SA- and JA-inducing oomycete pathogen Pythium irregulare, no significant effect of endogenous SA 
accumulation on JA biosynthesis was observed (Adie et al. 2007). In this study, analysis of the JA-responsive JA biosynthesis genes $L O X 2, A O S$, AOC2, and $O P R 3$ revealed that all were down regulated by exogenous application of SA (Fig. 2), confirming our hypothesis that the JA biosynthesis pathway is a potential target of the antagonistic effect of SA on JA signaling in Arabidopsis.

To investigate the significance of the JA biosynthesis pathway as a target in the suppression of JA signaling by $\mathrm{SA}$, we tested the antagonistic effect of SA on the expression of the JA-responsive marker gene PDF1.2 in the background of various JA biosynthesis mutants. Mutant aos/dde2 appeared to be the only genotype tested that was fully blocked in the ability to express the JA-responsive marker genes $P D F 1.2$ and $V S P 2$ in response to endogenous stimulation of the JA biosynthesis pathway by pathogen or insect attack (Fig. 3). Nevertheless, induction of PDF1.2 transcription in aos/dde2 by exogenous application of MeJA could be fully antagonized by SA (Fig. 4). Similar results were obtained for VSP2 (data not shown). Also in the other JA biosynthesis mutants tested, MeJA-induced PDF1.2 transcription was suppressed by SA to levels that were mostly similar as those observed in their respective wild-types. Interestingly, in the opr 3 mutant which is completely JA-deficient but can form OPDA (Stintzi et al. 2001; Delker et al. 2007) a similar suppression was found as in the aos/dde2 mutant, which confirms our findings in Fig. 1c that OPDA- and JAs-induced expression of PDF1.2 are similarly sensitive to suppression by SA. This is worthwhile to mention since evidence is accumulating that OPDA and JAs can differentially activate JA-responsive gene expression (Müller and Berger 2009). Collectively, these results indicate that downregulation of the JA biosynthesis pathway is not essential for SA-mediated suppression of JA signaling. Hence, we conclude that the antagonistic effect of SA on JA signaling acts at a target in the JA signaling pathway that functions downstream of JA biosynthesis. This conclusion is supported by the observation that $P D F 1.2$ transcription by exogenous application of saturating doses of MeJA (up to $2 \mathrm{mM}$ ) could still be antagonized by SA (Leon-Reyes et al. 2010), which makes it very unlikely that the suppressive effect of SA on JA signaling acts via the inhibition of JA biosynthesis. However, because several JA biosynthesis genes are upregulated upon activation of the JA signaling pathway, it can not be ruled out that suppression of their expression by SA may eventually contribute to the attenuation of the JA response during plant-attacker interactions.

So what are the potential target sites for the SA-mediated suppression of the JA signaling pathway downstream of JA biosynthesis? The $\mathrm{SCF}^{\mathrm{COI}}$-complex and JAZ repressor proteins are central components in the perception and transcriptional response to JAs. Mechanisms by which SA prevents JA-mediated degradation of JAZ proteins via the proteasome would suppress JA-responsive gene expression, and thus provide a potential explanation for the mode of action of SA-JA crosstalk. Alternatively, SA may activate negative regulators of JA-responsive gene expression that either inactivate or outcompete positive regulators. Currently, we are in the process of investigating these scenarios.

Acknowledgments We thank Ruth Joosten, Hans Van Pelt and Ientse Van der Sluis (Plant-Microbe Interactions, Utrecht University) for technical assistance. We thank the following colleagues for kindly sending Arabidopsis seeds: Prof. Keller and Dr. Ringli (University of Zürich, Switzerland; aos/dde2-2), Prof. Browse (Washington State University, Pullman, USA; opr3) and Dr. Brinder (University of Wisconsin, Madison, USA; aim1). This work was supported by VICI grant no. 865.04.002 of the Earth and Life Sciences Foundation, which is subsidized by the Netherlands Organization of Scientific Research.

Open Access This article is distributed under the terms of the Creative Commons Attribution Noncommercial License which permits any noncommercial use, distribution, and reproduction in any medium, provided the original author(s) and source are credited.

\section{References}

Adie BAT, Perez-Perez J, Perez-Perez MM, Godoy M, SanchezSerrano JJ, Schmelz EA, Solano R (2007) ABA is an essential signal for plant resistance to pathogens affecting JA biosynthesis and the activation of defenses in Arabidopsis. Plant Cell 19:1665-1681

Bell E, Mullet JE (1993) Characterization of an Arabidopsislipoxygenase gene responsive to methyl jasmonate and wounding. Plant Physiol 103:1133-1137

Bodenhausen N, Reymond P (2007) Signaling pathways controlling induced resistance to insect herbivores in Arabidopsis. Mol Plant Microbe Interact 20:1406-1420

Bostock RM (2005) Signal crosstalk and induced resistance: straddling the line between cost and benefit. Annu Rev Phytopathol 43:545-580

Broekaert WF, Terras FRG, Cammue BPA, Vanderleyden J (1990) An automated quantitative assay for fungal growth. FEMS Microbiol Lett 69:55-60

Browse J (2009) Jasmonate passes muster: a receptor and targets for the defense hormone. Annu Rev Plant Biol 60:183-205

Bruessow F, Gouhier-Darimont C, Buchala A, Métraux J-P, Reymond P (2010) Insect eggs suppress plant defence against chewing herbivores. Plant J 62:876-885

Cao H, Bowling SA, Gordon AS, Dong X (1994) Characterization of an Arabidopsis mutant that is nonresponsive to inducers of systemic acquired resistance. Plant Cell 6:1583-1592

Chini A, Fonseca S, Fernandez G, Adie B, Chico JM, Lorenzo O, Garcia-Casado G, Lopez-Vidriero I, Lozano FM, Ponce MR, Micol JL, Solano R (2007) The JAZ family of repressors is the missing link in jasmonate signalling. Nature 448:666-671

Chung HS, Niu Y, Browse J, Howe GA (2009) Top hits in contemporary JAZ: an update on jasmonate signaling. Phytochemistry 70:1547-1559

Cipollini D, Enright S, Traw MB, Bergelson J (2004) Salicylic acid inhibits jasmonic acid-induced resistance of Arabidopsis thaliana to Spodoptera exigua. Mol Ecol 13:1643-1653 
Cui J, Jander G, Racki LR, Kim PD, Pierce NE, Ausubel FM (2002) Signals involved in Arabidopsis resistance to Trichoplusia ni caterpillars induced by virulent and avirulent strains of the phytopathogen Pseudomonas syringae. Plant Physiol 129:551-564

De Vos M, Van Oosten VR, Van Poecke RMP, Van Pelt JA, Pozo MJ, Mueller MJ, Buchala AJ, Métraux JP, Van Loon LC, Dicke M, Pieterse CMJ (2005) Signal signature and transcriptome changes of Arabidopsis during pathogen and insect attack. Mol Plant Microbe Interact 18:923-937

Delker C (2005) Jasmonatbiosynthese in Arabidopsis thaliana Charakterisierung der Allenoxidcyclase-Genfamilie und von Mutanten der Fettsäure-B-oxidation. Ph.D thesis, Marthin Luther University Halle-Wittenberg, Germany

Delker C, Zolman BK, Miersch O, Wasternack C (2007) Jasmonate biosynthesis in Arabidopsis thaliana requires peroxisomal betaoxidation enzymes-Additional proof by properties of pex6 and aim1. Phytochemistry 68:1642-1650

Doherty HM, Selvendran RR, Bowles DJ (1988) The wound response of tomato plants can be inhibited by aspirin and related hydroxybenzoic acids. Physiol Mol Plant Pathol 33:377-384

Farmer EE, Alméras E, Krishnamurthy V (2003) Jasmonates and related oxylipins in plant responses to pathogenesis and herbivory. Curr Opin Plant Biol 6:372-378

Fonseca S, Chini A, Hamberg M, Adie B, Porzel A, Kramell R, Miersch O, Wasternack C, Solano R (2009) (+)-7-iso-Jasmonoyl-L-isoleucine is the endogenous bioactive jasmonate. Nat Chem Biol 5:344-350

Gfeller A, Dubugnon L, Liechti R, Farmer EE (2010) Jasmonate biochemical pathway. Sci Signal 3:cm3

Grant MR, Jones JDG (2009) Hormone (dis)harmony moulds plant health and disease. Science 324:750-752

Gupta V, Willits MG, Glazebrook J (2000) Arabidopsis thaliana EDS4 contributes to salicylic acid (SA)-dependent expression of defense responses: evidence for inhibition of jasmonic acid signaling by SA. Mol Plant Microbe Interact 13:503-511

Howe GA, Jander G (2008) Plant immunity to insect herbivores. Annu Rev Plant Biol 59:41-66

Jones JDG, Dangl JL (2006) The plant immune system. Nature 444:323-329

Koo AJK, Chung HS, Kobayashi Y, Howe GA (2006) Identification of a peroxisomal acyl-activating enzyme involved in the biosynthesis of jasmonic acid in Arabidopsis. J Biol Chem 281:33511-33520

Koornneef A, Pieterse CMJ (2008) Cross-talk in defense signaling. Plant Physiol 146:839-844

Koornneef A, Leon-Reyes A, Ritsema T, Verhage A, Den Otter FC, Van Loon LC, Pieterse CMJ (2008) Kinetics of salicylatemediated suppression of jasmonate signaling reveal a role for redox modulation. Plant Physiol 147:1358-1368

Laudert D, Weiler EW (1998) Allene oxide synthase: a major control point in Arabidopsis thaliana octadecanoid signalling. Plant $\mathrm{J}$ 15:675-684

Leon-Reyes A, Spoel SH, De Lange ES, Abe H, Kobayashi M, Tsuda $\mathrm{S}$, Millenaar FF, Welschen RAM, Ritsema T, Pieterse CMJ (2009) Ethylene modulates the role of NONEXPRESSOR OF PATHOGENESIS-RELATED GENES1 in cross talk between salicylate and jasmonate signaling. Plant Physiol 149:1797-1809

Leon-Reyes A, Du Y, Koornneef A, Proietti S, Körbes AP, Memelink J, Pieterse CMJ, Ritsema T (2010) Ethylene signaling renders the jasmonate response of Arabidopsis insensitive to future suppression by salicylic acid. Mol Plant Microbe Interact 23:187-197

Memelink J (2009) Regulation of gene expression by jasmonate hormones. Phytochemistry 70:1560-1570

Miersch O, Neumerkel J, Dippe M, Stenzel I, Wasternack C (2008) Hydroxylated jasmonates are commonly occurring metabolites of jasmonic acid and contribute to a partial switch-off in jasmonate signaling. New Phytol 177:114-127

Müller MJ, Berger S (2009) Reactive electrophilic oxylipins: pattern recognition and signaling. Phytochemistry 70:1511-1521

Mur LAJ, Kenton P, Atzorn R, Miersch O, Wasternack C (2006) The outcomes of concentration-specific interactions between salicylate and jasmonate signaling include synergy, antagonism, and oxidative stress leading to cell death. Plant Physiol 140:249-262

Norton G, Pappusamy A, Yusof F, Pujade-Renaud V, Perkins M, Griffiths D, Jones H (2007) Characterisation of recombinant Hevea brasiliensis allene oxide synthase: effects of cycloxygenase inhibitors, lipoxygenase inhibitors and salicylates on enzyme activity. Plant Physiol Biochem 45:129-138

Pan Z, Camara B, Gardner HW, Backhaus RA (1998) Aspirin inhibition and acetylation of the plant cytochrome P450, allene oxide synthase, resembles that of animal prostaglandin endoperoxide H synthase. J Biol Chem 273:18139-18145

Park J-H, Halitschke R, Kim HB, Baldwin IT, Feldmann KA, Feyereisen R (2002) A knock-out mutation in allene oxide synthase results in male sterility and defective wound signal transduction in Arabidopsis due to a block in jasmonic acid biosynthesis. Plant J 31:1-12

Pauwels L, Inzé D, Goossens A (2009) Jasmonate-inducible gene: what does it mean? Trends Plant Sci 14:87-91

Peña-Cortés H, Albrecht T, Prat S, Weiler EW, Willmitzer L (1993) Aspirin prevents wound-induced gene expression in tomato leaves by blocking jasmonic acid biosynthesis. Planta 191:123-128

Pieterse CMJ, Dicke M (2007) Plant interactions with microbes and insects: from molecular mechanisms to ecology. Trends Plant Sci 12:564-569

Pieterse CMJ, Leon-Reyes A, Van der Ent S, Van Wees SCM (2009) Networking by small-molecules hormones in plant immunity. Nature Chem Biol 5:308-316

Pozo MJ, Van der Ent S, Van Loon LC, Pieterse CMJ (2008) Transcription factor MYC2 is involved in priming for enhanced defense during rhizobacteria-induced systemic resistance in Arabidopsis thaliana. New Phytol 180:511-523

Richmond TA, Bleecker AB (1999) A defect in $\beta$-oxidation causes abnormal inflorescence development in Arabidopsis. Plant Cell 11:1911-1923

Sasaki Y, Asamizu E, Shibata D, Nakamura Y, Kaneko T, Awai K, Amagai M, Kuwata C, Tsugane T, Masuda T, Shimada H, Takamiya X, Ohta H, Tabata S (2001) Monitoring of methyl jasmonate-responsive genes in Arabidopsis by cDNA macroarray: self-activation of jasmonic acid biosynthesis and crosstalk with other phytohormone signaling pathways. DNA Res 8:153-161

Seo HS, Song JT, Cheong J-J, Lee Y-H, Lee Y-W, Hwang I, Lee JS, Choi YD (2001) Jasmonic acid carboxyl methyltransferase: a key enzyme for jasmonate-regulated plant responses. Proc Natl Acad Sci USA 98:4788-4793

Spoel SH, Koornneef A, Claessens SMC, Korzelius JP, Van Pelt JA, Mueller MJ, Buchala AJ, Métraux J-P, Brown R, Kazan K, Van Loon LC, Dong X, Pieterse CMJ (2003) NPR1 modulates crosstalk between salicylate- and jasmonate-dependent defense pathways through a novel function in the cytosol. Plant Cell 15:760-770

Spoel SH, Johnson JS, Dong X (2007) Regulation of tradeoffs between plant defenses against pathogens with different lifestyles. Proc Natl Acad Sci USA 104:18842-18847

Staswick PE, Tiryaki I (2004) The oxylipin signal jasmonic acid is activated by an enzyme that conjugates it to isoleucine in Arabidopsis. Plant Cell 16:2117-2127

Staswick PE, Yuen GY, Lehman CC (1992) Methyl jasmonate inhibition of root growth and induction of a leaf protein are 
decreased in an Arabidopsis thaliana mutant. Proc Natl Acad Sci USA 89:6837-6840

Stenzel I, Hause B, Miersch O, Kurz T, Maucher H, Weichert H, Ziegler J, Feussner I, Wasternack C (2003) Jasmonate biosynthesis and the allene oxide cyclase family of Arabidopsis thaliana. Plant Mol Biol 51:895-911

Stintzi A, Browse J (2000) The Arabidopsis male-sterile mutant, opr3, lacks the 12-oxophytodienoic acid reductase required for jasmonate synthesis. Proc Natl Acad Sci USA 97:10625-10630

Stintzi A, Weber H, Reymond P, Browse J, Farmer EE (2001) Plant defense in the absence of jasmonic acid: the role of cyclopentenones. Proc Natl Acad Sci USA 98:12837-12842

Straus DS, Glass CK (2001) Cyclopentenone prostaglandins: new insights on biological activities and cellular targets. Med Res Rev 21:185-210

Thines B, Katsir L, Melotto M, Niu Y, Mandaokar A, Liu GH, Nomura K, He SY, Howe GA, Browse J (2007) JAZ repressor proteins are targets of the $\mathrm{SCF}^{\mathrm{COI} 1}$ complex during jasmonate signalling. Nature 448:661-665

Van der Ent S, Verhagen BWM, Van Doorn R, Bakker D, Verlaan MG, Pel MJC, Joosten RG, Proveniers MCG, Van Loon LC, Ton J, Pieterse CMJ (2008) MYB72 is required in early signaling steps of rhizobacteria-induced systemic resistance in Arabidopsis. Plant Physiol 146:1293-1304

Van der Ent S, Van Hulten MHA, Pozo MJ, Czechowski T, Udvardi MK, Pieterse CMJ, Ton J (2009a) Priming of plant innate immunity by rhizobacteria and $\beta$-aminobutyric acid: differences and similarities in regulation. New Phytol 183:419-431

Van der Ent S, Van Wees SCM, Pieterse CMJ (2009b) Jasmonate signaling in plant interactions with resistance-inducing beneficial microbes. Phytochemistry 70:1581-1588

Van Oosten VR, Bodenhausen N, Reymond P, Van Pelt JA, Van Loon LC, Dicke M, Pieterse CMJ (2008) Differential effectiveness of microbially induced resistance against herbivorous insects in Arabidopsis. Mol Plant Microbe Interact 21:919-930

Van Wees SCM, Luijendijk M, Smoorenburg I, Van Loon LC, Pieterse CMJ (1999) Rhizobacteria-mediated induced systemic resistance (ISR) in Arabidopsis is not associated with a direct effect on expression of known defense-related genes but stimulates the expression of the jasmonate-inducible gene Atvsp upon challenge. Plant Mol Biol 41:537-549

Verhage A, Van Wees SCM, Pieterse CMJ (2010) Plant immunity: it's the hormones talking, but what do they say? Plant Physiol (in press)

Von Malek B, Van der Graaff E, Schneitz K, Keller B (2002) The Arabidopsis male-sterile mutant dde2-2 is defective in the ALLENE OXIDE SYNTHASE gene encoding one of the key enzymes of the jasmonic acid biosynthesis pathway. Planta 216:187-192

Walling LL (2008) Avoiding effective defenses: strategies employed by phloem-feeding insects. Plant Physiol 146:859-866

Wasternack C (2007) Jasmonates: an update on biosynthesis, signal transduction and action in plant stress response, growth and development. Ann Bot 100:681-697

Yan J, Zhang C, Gu M, Bai Z, Zhang W, Qi T, Cheng Z, Peng W, Luo H, Nan F, Wang Z, Xie D (2009) The Arabidopsis CORONATINE INSENSITIVE1 protein is a jasmonate receptor. Plant Cell 21:2220-2236

Zander M, La Camera S, Lamotte O, Métraux J-P, Gatz C (2009) Arabidopsis thaliana class-II TGA transcription factors are essential activators of jasmonic acid/ethylene-induced defense responses. Plant J 61:200-210

Zarate SI, Kempema LA, Walling LL (2007) Silverleaf whitefly induces salicylic acid defenses and suppresses effectual jasmonic acid defenses. Plant Physiol 143:866-875 